\title{
Os diferentes empregos da palavra experiência nas publicações sobre a Gestão Autônoma da Medicação no Brasil
}

\author{
The different uses of the word experience in publications on Autonomous \\ Medication Management in Brazil
}

Lívia Zanchet

Universidade Federal do Rio Grande do Sul

\section{RESUMO:}

Este artigo discute a noção de experiência nas publicações sobre a estratégia da Gestão Autônoma da Medicação no Brasil, no período de 2009 a 2018. É fruto de uma análise documental de dados secundários, em que foram material prioritário de análise os artigos publicados no período. São interlocutores destas análises Walter Benjamin, Giorgio Agamben e Jorge Larrosa. Apresentamos os diferentes empregos que a noção de experiência ganha nos textos, com ênfase para a diferença entre dois campos semânticos: o primeiro, onde ela vai significar aquilo que o sujeito vive ou experimenta; e o segundo, o qual entendemos mais forte e relevante para o campo da saúde mental, onde ela vai significar aquilo que resta da travessia de um perigo. Nosso mergulho nessas publicações nos permitiu afirmar que a GAM tem se constituído como uma experiência nesse segundo sentido para seus participantes, sejam eles usuários, familiares, trabalhadores ou pesquisadores.

Palavras-chave: experiência; Gestão Autônoma da Medicação; saúde mental

\section{ABSTRACT:}

This article discusses the notion of experience in publications on the strategy of Autonomous Management of Medication in Brazil in the period from 2009 to 2018. It is the result of a documentary analysis of secondary data, in which the articles published in the period were priority material. Our interlocutors are Walter Benjamin, Giorgio Agamben and Jorge Larrosa. We present the different usages that the notion of experience gains in the texts, with an emphasis on the difference between two senses: one, which it will mean what the subject lives or experiences; other, which we consider stronger and more relevant to the mental health discussions, where it will mean what remains of crossing a danger. Our dive into these publications allowed us to affirm that GAM has been constituted as an experience in this second sense for its participants, whether they are users, family members, workers or researchers.

Key-words: experience; Autonomous Medication Management; mental health 


\section{Introdução}

Neste artigo apresentamos resultados de uma pesquisa de doutorado que investigou a noção de experiência presente nas publicações sobre a Gestão Autônoma da Medicação (GAM) no Brasil. A GAM é uma estratégia originária do Québec/Canadá, que busca aumentar o poder de negociação dos usuários atendidos nos serviços da rede de saúde mental em relação à tomada de decisão nos tratamentos medicamentosos que lhes são propostos, de forma a ampliar o diálogo entre usuário e equipe de saúde, bem como com os demais atores envolvidos no cuidado. Ela tem como princípios a cogestão e a autonomia ${ }^{1}$, sendo um processo de aprendizado e trocas sobre o uso de medicamentos psiquiátricos e seus efeitos em todos os aspectos da vida do usuário. Sua chegada no Brasil se deu em 2009 por meio de um projeto multicêntrico envolvendo inicialmente quatro universidades públicas brasileiras (Unicamp, UFRJ, UFF e UFRGS), em parceria com a Universidade de Montreal, por meio da Aliança Internacional de Pesquisa Universidade-Comunidade - Saúde Mental e Cidadania (ARUCi), do Quebec/Canadá. Foi um trabalho desenvolvido em diferentes etapas no curso destes dez anos.

A primeira delas esteve voltada à construção da versão brasileira do Guia da Gestão Autônoma da Medicação, o Guia GAM-BR (ONOCKO-CAMPOS et alli, 2014). Neste processo, realizou-se a tradução e adaptação do material canadense intitulado Gestion autonome de la médication de l'âme (GAM): Mon Guide Personnel ${ }^{2}$. No Quebec, o uso do guia estava voltado a auxiliar o sujeito a se reposicionar frente às questões de seu tratamento farmacológico junto ao médico prescritor. No Brasil, a construção do Guia previa, desde o princípio, seu uso como dispositivo grupal nos serviços do Sistema Único de Saúde (SUS). A versão brasileira impressa foi lançada em 2013.

A primeira etapa da pesquisa (anos de 2009 e 2010) teve como arranjo operacional a realização de quatro Grupos de Intervenção (GI): três deles em Centros de Atenção Psicossocial (CAPS) em diferentes cidades brasileiras e um quarto junto a uma das universidades integrantes da pesquisa, com a participação de membros da associação local de usuários e familiares da saúde mental.

Além dos GIs, o acompanhamento da experiência se fez por meio de grupos focais com os usuários participantes e entrevistas com gestores e com os trabalhadores de cada local. Também foram escritas "memórias" dos grupos realizados, como eram chamados os relatos 
dos encontros produzidos pelos pesquisadores em diários de campo. O material colhido foi trabalhado por meio do método narrativo proposto por Onocko Campos e Furtado (2008). Durante esta primeira etapa, grupo de pesquisa composto pelos três campos reuniu-se em encontros multicêntricos, onde se construíram os pactos concernentes ao funcionamento geral da pesquisa ao longo do seu primeiro ano de realização e, no segundo ano, em torno da construção da versão brasileira do Guia GAM. Alguns anos passados da realização deste trabalho, pensamos não mais ser possível dizer que o material fora traduzido e adaptado à realidade brasileira; mas, transformado ${ }^{3}$.

A segunda etapa foi a de validação do material produzido (entre 2011 e 2013), por meio de sua aplicação crítica. Desta vez, o trabalho aconteceu envolvendo as mesmas instituições acadêmicas, mas incluindo outros serviços de saúde mental. O final desta etapa se deu com o lançamento público do Guia GAM-BR, em março de 2013. Um ano depois, o grupo lançou o Guia do Moderador, material de apoio para os interessados na moderação de grupos GAM, com orientações e diretrizes gerais para utilização do Guia GAM-BR

Mesmo com a finalização oficial prevista pelo projeto multicêntrico, em 2014 a GAM seguiu existindo e se disseminando pelo Brasil e no exterior. Um número especial da revista Polis e Psique (FERRER, PALOMBINI e ARAÚJO, 2020) aborda alguns destes trabalhos que ganharam espaço no Rio Grande do Sul, Rio de Janeiro, Espírito Santo, São Paulo, Alagoas, Rio Grande do Norte e mesmo na Espanha, com uma nova versão do Guia publicada neste país, então chamado Guía de la gestión colaborativa de la medicación en salud mental (SERRANOMIGUEL, PIÉ-BALAGUER e MARTÍNEZ-HERNAEZ, 2020).

Em 2017, foi lançado o “Observatório Internacional das Práticas da Gestão Autônoma da Medicação: escola colaborativa de produção de conhecimento, apoio e fomento", projeto multicêntrico coordenado pela Universidade Federal de São Paulo (Unifesp), que segue acompanhando a disseminação da $\mathrm{GAM}^{4}$.

\section{Metodologia}

\section{Publicações, o terreno da pesquisa}

Neste período de dez anos de trabalho em torno ao tema da GAM no Brasil, entre parcerias internacionais, nacionais e regionais, inúmeras foram as publicações resultantes, entre teses, dissertações e artigos. Há, ainda, outras produções, como trabalhos de conclusão de curso de graduação e especialização, apresentações de bolsistas de iniciação científica e 
apresentações de trabalhos em congressos e eventos de extensão, além de sites, blogs, entrevistas e vídeos. É o conjunto destas produções, em especial o dos artigos publicados, que compôs o terreno de nossa pesquisa de doutorado, baseada em análise documental de dados secundários.

A escolha por uma análise mais aprofundada do texto da totalidade dos artigos publicados no período se deu considerando o grande número de trabalhos publicados e por serem os artigos produções de maior acesso e alcance de disseminação na comunidade científica, além de seu caráter de condensar e sistematizar aquilo que de fundamental as pesquisas produziram. Uma primeira leitura deste material apontou para a relevância do termo "experiência", o qual aparecia de forma bastante frequente e ia ganhando diferentes sentidos. Nas páginas que seguem, apresentamos e discutimos os diferentes empregos da palavra experiência presentes nos quase trinta artigos publicados entre os anos de 2011 e 2018, tomando-a como uma noção articuladora de nossas reflexões.

\section{Ferramentas na travessia}

Para nos acompanhar nessa travessia, lançamos mão da companhia de autores já consagrados, entre outros, pela discussão a respeito do tema da experiência em suas obras. São eles Walter Benjamin, Giorgio Agamben e Jorge Larrosa. Deste último, um livro recém publicado circulava à época pelas discussões do grupo de pesquisa, Tremores: escritos sobre experiência (LARROSA, 2014), e sua leitura propulsionou o processo de encontro com as ideias dos outros dois autores.

Além deles, nossos autores "locais", os pesquisadores da GAM, são também parceiros fundamentais, a partir de suas análises, que comparecem com frequência no texto. Estivemos munidos dos aportes teóricos da pesquisa narrativa que nos propõe Rosana Onocko Campos, pesquisadora responsável por trazer a GAM para o Brasil. É sua e de um colega a metodologia de trabalho com narrativas a partir de extração de seus núcleos argumentais. (ONOCKO CAMPOS \& FURTADO, 2008). Nossa leitura dos artigos serve-se desta metodologia, onde o que importa são as ideias-chave presentes na narrativa, que vão compondo os núcleos argumentativos, os quais vão servir a temas maiores. Assim, buscamos também no texto as ideias-chave e seus núcleos argumentativos, sempre que nos encontramos com a presença do termo "experiência". 
Consideramos que foi também ferramenta de pesquisa e análise a própria noção de experiência que desenvolvemos e que nos serviu de guia, a qual apresentamos a seguir. Nossa leitura respeitou a cronologia das publicações, começando pela mais antiga, no intuito de traçar um acompanhamento desta produção também pela via temporal.

\section{Experiência - vários artigos, uma palavra, muitos sentidos}

Experiência, expertise, experimento... temos aí uma raiz comum mas, na sua construção, cada uma dessas palavras foi assumindo diferentes sentidos e produzindo diferentes efeitos a partir de seus usos no cotidiano e na literatura científica. Apostamos no valor de investigar com mais profundidade os empregos da palavra experiência nas produções GAM, de forma a precisar quais são os sentidos aí implicados e seus efeitos, bem como melhor compreender que produção de conhecimento a GAM vem construindo no que diz respeito ao emprego desta noção e no que - e se - isso se diferencia do senso comum.

Ao partir da etimologia da palavra "experiência", encontramos, conforme consta no Grande Dicionário da Língua Portuguesa (HOUAISS \& VILLAR, 2001), sua origem latina no verbo periri (tentar, provar, empreender, experimentar), do qual restou o particípio passado peritus, que passou diretamente para o português como perito, habilidoso, experimentado. Com a adição da preposição "ex" surge no latim experientia, que significa prova, ensaio, tentativa e, no latim imperial, experiência adquirida. Assim, o termo experiência pode significar tanto uma tentativa, uma prova, num sentido mais objetivo de algo que se faz, como o que resta de aprendido a partir de várias provas no decorrer da própria vida. O mesmo radical de periri está na palavra periculum (tentativa, prova, risco, exame) e no adjetivo periculosum (arriscado, perigoso). No português vamos encontrar então as palavras experiência, perigo, perigoso, perito, todas como derivações de um mesmo radical.

O termo experiência significa na sua origem, portanto, o que foi retirado (-ex) de uma prova ou provação (-perientia), algo que foi adquirido de um contato com o mundo, mas também aquilo que aí resta, algo da ordem da travessia de uma prova, de um perigo.

Como já dissemos, usa-se frequentemente a palavra experiência nas produções GAM; no entanto, dada a vastidão de sentidos que esta palavra pode assumir, seu emprego pode se esvaziar de significação e importância, ou mesmo generalizar aquilo que mais deveria ser singularizado. 
Nossa busca nos levou ao encontro com Jorge Larrosa, em um livro publicado em 2014, com o título Tremores: escritos sobre experiência. As várias passagens que abordam tal noção vão nos ajudando a ressituá-la e a tomá-la a partir de um referencial único, que contrapõe o senso comum na sua simples relação ao que foi vivido pelo ser humano. Os escritos de Larrosa vêm na esteira do pensamento de Walter Benjamin e Giorgio Agamben, os quais também se dedicaram a abordar a noção de experiência e são referência para aqueles que trabalham com esta temática.

A seguir, apresentaremos um apanhado das passagens sobre experiência propostas por Larrosa, buscando não só revelar, mas também propor um conceito com o qual operaremos nosso olhar sobre os artigos publicados em torno à Gestão Autônoma da Medicação. Seus escritos colocam a experiência como aquilo que resta de uma travessia. "A experiência é o que nos passa, o que nos acontece, o que nos toca. Não o que se passa, o que acontece, ou o que toca" (LARROSA, 2014: 11). A partir desta ideia, e na companhia do pensamento de Walter Benjamin e de Giorgio Agamben, Larrosa vai afirmar que a experiência está cada vez mais rara nos dias de hoje, dado o excesso de informação e de opiniões em que estamos mergulhados cotidianamente. Estas tornam-se uma barreira a que algo de fato nos aconteça, dada a rapidez dos eventos de todos os dias. Este excesso de excitação e estímulos a que estamos submetidos dificulta o processo de experienciar algo. "A velocidade e o que ela provoca, a falta de silêncio e de memória, são também inimigos mortais da experiência" (LARROSA, 2014: 14).

Larrosa vai abordar a questão "Quem é o sujeito da experiência?” propondo uma torção na ideia de que o sujeito se define por sua atividade. Segundo ele, o sujeito da experiência se caracteriza por sua passividade, por sua receptividade, por sua disponibilidade e sua abertura. Ele é um território de passagem, um espaço onde têm lugar os acontecimentos e nunca um sujeito de saber, de poder, do fazer, do julgar ou do querer. Ele se utiliza do que diz Heidegger (2003) em “A essência da linguagem”, para afirmar que o sujeito da experiência seria um sujeito alcançado, derrubado, tombado; nunca um sujeito que permanece em pé, erguido, ereto e seguro de si mesmo. Este último não abre possibilidade para a experiência.

Longe de ser um simples fato ocorrido, uma simples situação vivida, a experiência submete o sujeito, apodera-se dele; jamais o contrário. Ela tem como componente fundamental sua capacidade de formar e de transformar. Lembrando a etimologia da palavra, como já situamos acima, Larrosa retoma o radical peri, o mesmo presente em perigo e, portanto, a relação originária da palavra experiência como aquilo que resta da travessia de um perigo. 
Como já anunciamos, Larrosa discute a noção de experiência a partir de seu trabalho e pesquisas no campo da educação; somos nós que estamos propondo fazer uso do que encontramos em sua obra para a discussão no campo da saúde mental. Em suas proposições, o autor afirma a importância de se "reivindicar a experiência e fazer soar de outro modo a palavra experiência" (LARROSA, 2014: 26); no entanto, na contramão do que aqui fazíamos até agora, ele afirma a importância de se reivindicar esta experiência como aquilo que não se pode conceituar, o que resiste a qualquer conceito que queira determiná-la. Portanto, não como aquilo que é, mas como aquilo que acontece.

Aqui, voltamos à GAM e sua proposta mais originária: possibilitar e mesmo estimular um lugar de fala sobre a experiência de uso de psicofármacos Desta proposta originária, contudo, outras se desdobram e fazem com que a palavra experiência seja empregada inúmeras vezes para se referir ao que aí acontece. Temos então a experiência dos grupos GAM, a experiência de fazer com, a experiência de ser usuário neste processo, a de ser trabalhador e mesmo pesquisador; temos a experiência de escrever juntos, as experiências nas escolas e com as crianças, as experiências com as substâncias ilícitas... e mesmo a experiência GAM.

Todos estes empregos da palavra experiência se assemelham? Se sim, de que experiência estamos tratando? Será que a experiência de que tratam as publicações GAM é esta que envolve a travessia de um perigo, que se refere ao que resta dessa travessia e é ingerenciável? Ou o que se encontra nestas produções seria apenas a experiência como o engodo do domínio sobre o não-dominável? E, neste caso, quando estaríamos empregando experiência no sentido desejável e quando não?

Contudo, ao falarmos desse algo que resta, precisemos que é um resto passível de elaboração, conforme acompanhamos nas proposições de Walter Benjamin. Seus escritos estão situados no século XX - período de guerras, de regimes fascistas e autoritários, o qual aparece, segundo o autor, como uma espécie de século da não-experiência, em que, dadas as condições e o excesso de precariedades, o homem estava impossibilitado de elaborar suas experiências e, por consequência, de transmiti-las. Em "Experiência e Pobreza" (2011), Benjamin fala sobre este declínio da experiência na modernidade. Ele utiliza como exemplo a volta dos soldados depois da primeira grande guerra mundial, os quais retornam emudecidos, sem possibilidade de dizer algo a respeito do que viveram. Não é à toa que, após a Segunda Grande Guerra Mundial, surgem inúmeros tratados internacionais dedicados a abordar os direitos humanos e 
as pessoas em situação de maior vulnerabilidade. Viu-se aí a radicalização da importância de se proteger os direitos humanos de forma universal.

No início do texto, Benjamin usa uma narrativa lendária sobre como nos tornamos ricos. Ela envolve pai e filhos na ideia de que a riqueza provém da experiência transmitida entre as gerações, daquilo que é passível de ser compartilhado e não do acúmulo individual de qualquer bem ou produto. Desta forma, o autor faz uso de dois vocábulos alemães - Erfahrung e Erlebnis - para diferenciar o que em nossa tradução tomamos por Experiência (Erfahrung), atualizando aquilo que fica, o que se elabora de algo que se vive; e o que traduzimos por Vivência (Erlebnis), a qual estaria mais voltada ao individual do acontecimento e a um tempo imediato, sem duração, característico do capitalismo - vivência seria a pura emoção do instante vivido. (GAGNEBIN, 2011).

A ideia de experiência estaria mais conectada ao coletivo que ao individual, já que se refere a algo que pode ser passado adiante, enriquecendo aquilo que se vive também para quem transmite. É no ato da transmissão que a vivência ganha o estatuto de experiência, de modo que não faz sentido, em Benjamin, a perspectiva de experiência individual. É nesta direção que vemos aparecer a experiência nas produções GAM - algo que, ao ser contado, colocado em palavras, assume um outro estatuto e intervém sobre outras narrativas. Portanto, na GAM, todos aqueles que intervêm experimentam também uma intervenção a partir do processo de que fazem parte. A troca faz-se um dos principais motores desse trabalho, ampliando-se o olhar e o entendimento sobre as vivências. Benjamin (1994) vai afirmar, em "O narrador", que este era a figura que transmitia experiências, pois à narrativa ele atribui a faculdade de intercambiar experiências. Esta busca reavivar algo que a ciência, na intenção de construir um saber válido e verdadeiro, acabou abandonando, uma vez que os textos carregam, em sua maioria, um vazio de vida, uma impessoalidade e uma solidão que lhes é característica. A narrativa carrega nela mesma o narrador: "Quem escuta uma história está em companhia do narrador, mesmo quem lê partilha dessa companhia.” (BENJAMIN, 1994: 213). Ao se pesquisar via narrativa, estamos de início marcando a inseparabilidade entre sujeito e objeto. Aquele que narra está envolvido naquilo que narra. Aquilo que é narrado está carregado dos afetos do narrador.

Na perspectiva benjaminiana, essas narrativas se produzem a partir dos restos, dos cacos colhidos no percurso. Narram-se os detalhes invisíveis e, a priori, desnecessários. Estes restos produzem rastros nem sempre intencionais. Rastros de que falará Benjamin, citando o seu desaparecimento consequente. Ele utiliza como pano de fundo de sua discussão as mudanças 
na dimensão arquitetônica das cidades no século XX em relação ao século XIX. A burguesia do século XIX tinha como marca a interiorização, a intimização da casa, do quarto, com o uso frequente do veludo, um material a carregar consigo as marcas que ficam quando algo ali se passa. Nesta época, a casa era o refúgio diante de um mundo exterior hostil e anônimo. Anos depois, o vidro veio substituir o veludo, trazendo a exposição do privado e, ao mesmo tempo, o apagamento dos rastros, uma vez que estes não poderiam mais se fixar na superfície agora lisa, transparente e não aderente.

Giorgio Agamben escreve a partir do pensamento benjaminiano, afirmando que, neste século, seguimos construindo relações e experimentando vivências que mantêm esse fluxo de apagamentos. Um exemplo atual seriam as redes sociais, que acabam funcionando como um empuxo ao não-encontro, ao excesso de opiniões, ao excesso de informações, à velocidade, à falta de brechas para que o sujeito se permita fazer uma travessia; é um ambiente onde nos deparamos com muitas certezas, discursos imperativos que afirmam verdades com pouca crítica e reflexão; há algo de autoritário que se impõe, além de toda a questão do forte apelo à imagem que aí encontramos.

A principal contribuição de Giorgio Agamben para a discussão a respeito da experiência aparece na obra "Infância e história: destruição da experiência e origem da história" (AGAMBEN, 2008 [2005]). Nela, o título pode fazer o leitor pensar equivocadamente que tratará da temática da infância, quando sua discussão será a respeito da possibilidade de expropriação da experiência do homem moderno. Ainda que ele concorde com a tese benjaminiana de que a Primeira Grande Guerra Mundial teria empobrecido a experiência dos soldados, devido às suas catástrofes, ele afirma que a existência cotidiana do homem moderno em uma grande cidade já seria suficiente para a destruição da experiência.

No primeiro ensaio do livro, Agamben sugere que o projeto da ciência moderna colocou em xeque a capacidade do homem de fazer e ter experiências; afinal, a imaginação fora capturada pelo conhecimento e a experiência fora transformada em experimentos: “[...] a ciência moderna nasce de uma desconfiança sem precedentes em relação à experiência como era tradicionalmente entendida (Bacon define-a "uma selva" e "um labirinto" nos quais se propõe a colocar ordem)" (AGAMBEN, 2008: 25)

O sujeito cartesiano, desapropriado de sua experiência, ficaria resumido ao eu penso, portanto um ser racional e emancipado. A experiência não necessariamente teria chegado ao fim, mas se daria fora do homem. O autor propõe aí uma aproximação entre experiência e 
linguagem, voltando à explicação de que o homem vai se constituir como um sujeito na e através da linguagem, pois ele não nasce já um ser falante. Ao contrário, o sujeito precisa viver uma infância (in-fancia), período onde ainda não fala, para constituir-se como sujeito falante na sua relação com o Outro. Desta forma, Agamben aproxima a experiência da infância do homem: "Como infância do homem a experiência é a simples diferença entre humano e linguístico. Que o homem não seja sempre já falante, que ele tenha sido e ainda seja in-fante, isto é a experiência". (AGAMBEN, 2008: 62). Essa infância seria o que permite ao homem a experiência para que se aproprie da língua entre no discurso, seria descontinuidade entre natureza e cultura; ela não seria, para Agamben uma simples etapa cronológica, mas uma potência que permite ao sujeito renunciar ao previsível e transformar o cotidiano, seria onde a experiência acontece. A infância coloca o indivíduo no lugar de produtor da cultura, onde, com outros interlocutores, ele acrescenta significação ao mundo (GOMES, 2007: 254). Segundọ Agamben, é essa qualidade que diferencia o humano de outros seres existentes.

A experiência como infância do homem coloca-o (nos) diante de uma grande possibilidade e também de uma grande responsabilidade em relação ao mundo.

\section{Resultados e Discussão}

\section{Os três planos da experiência GAM: os usuários, os serviços, a pesquisa}

De maneira geral, nossa leitura apontou para o uso da noção de experiência a partir de três grandes planos que se interrelacionam: a experiência dos usuários; a experiência dos/nos serviços (aqui consideramos também a experiência que aparece nomeada como dos trabalhadores/profissionais) e a experiência da pesquisa (ou do pesquisador). Vamos discorrer sobre elas, trazendo, por vezes, fragmentos dos artigos onde aparecem.

A figura abaixo apresenta, de forma esquemática e resumida, a discussão subsequente: 


\section{Figura 1}

\section{Os três contextos}
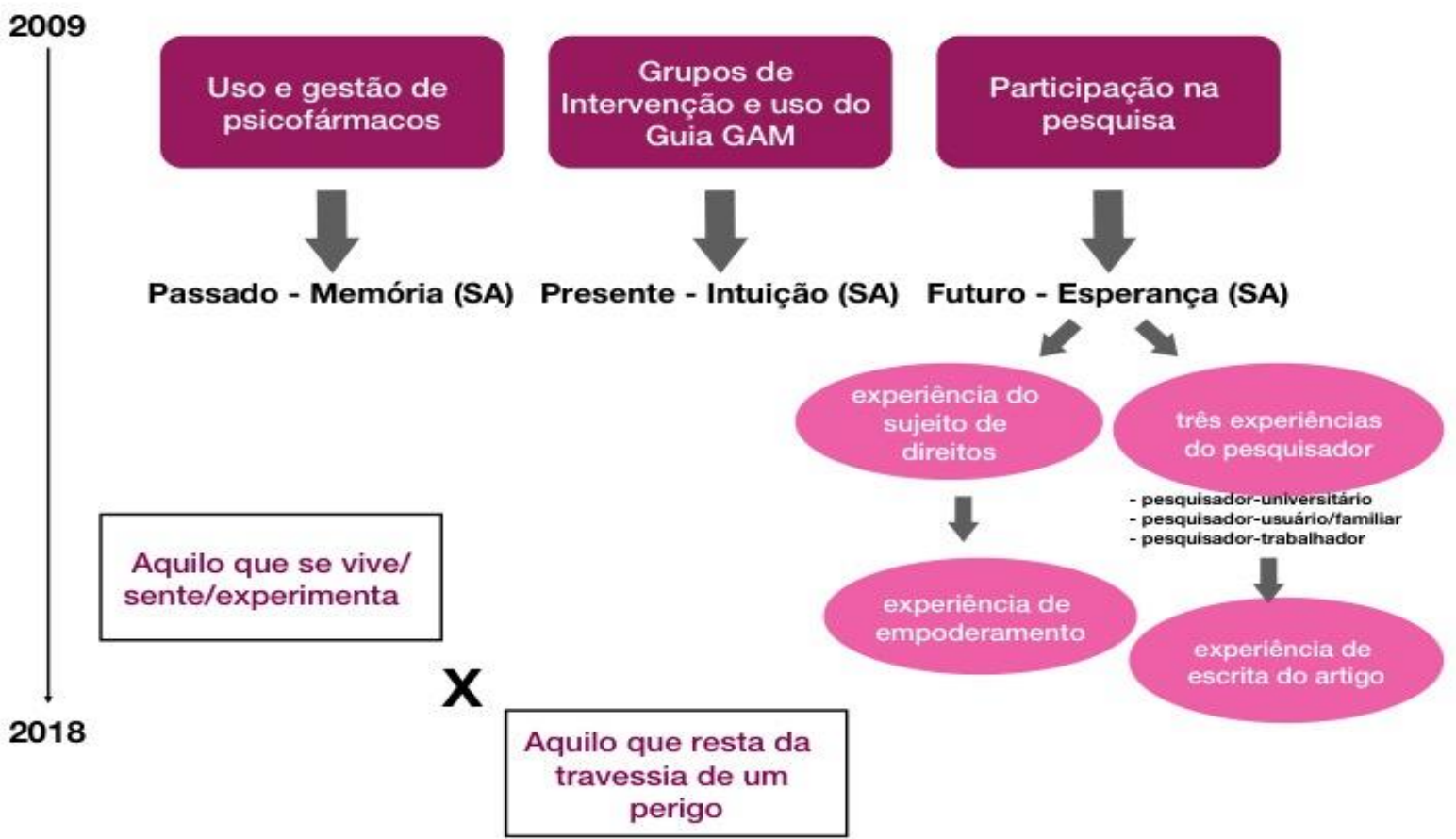

\section{Os três contextos}

Inicialmente apresentamos os três principais contextos em que a noção de experiência é empregada no conjunto dos artigos, propondo uma correspondência com os três planos já citados, que dizem da experiência dos usuários, dos serviços e da pesquisa:

a) O primeiro deles é o da experiência de uso e gestão de psicofármacos e diz respeito especialmente ao usuários que participaram da pesquisa-intervenção.

b) O segundo refere-se à experiência dos Grupos de Intervenção (GI) com o Guia GAM e a consequente emergência da experiência de cogestão. Em relação a esta última, fala-se com frequência na experiência dos usuários, mas a experiência dos serviços e dos trabalhadores aí 
presentes também pode aparecer, assim como a experiência dos pesquisadores. Trata-se de um uso da noção de experiência que deixa evidente a perspectiva de encontro proporcionado pelos grupos GAM e, portanto, a do atravessamento entre os três planos estruturantes de nossa busca. Os grupos de intervenção são o dispositivo principal da estratégia para proporcionar e potencializar este encontro entre os três distintos segmentos participantes do projeto.

c) O terceiro contexto refere-se à experiência de participação na pesquisa universitária. Aqui, o que aparece inicialmente está mais voltado à discussão da experiência dos usuários, mas, no decorrer do trabalho, é feita menção também à experiência dos trabalhadores e dos pesquisadores. Neste contexto, a discussão se amplia e aborda a participação dos familiares, já que algumas pesquisas destinaram-se a trabalhar especificamente com este segmento e colheram daí efeitos particulares.

Estes três contextos são recorrentes nas produções - alguns artigos ocupam-se de analisar de forma mais específica um ou outro; mas, de maneira geral, eles perpassam todas as publicações. É frequente que, nestes empregos, encontremos um sentido para a palavra experiência que se volta mais ao que Benjamin nomearia como vivência, pois se trata de algo por que o sujeito passou simplesmente, sem maiores consequências; algo que ele experimentou de maneira mais instantânea. Ao mesmo tempo, podemos perceber que o interesse principal nas escritas é o de abordar a experiência de fato, tratar de algo que se passou ao sujeito, relacionado aos sentidos de travessia, de elaboração, de aprender com, de se transformar no processo.

Outra possibilidade de caracterizar estes três contextos é pensá-los a partir de três tempos próprios à experiência - passado, presente e futuro -, porém, de uma forma mais complexa, tendo o presente como orientador. O primeiro desses contextos, que nos textos aparece como o de uso e gestão de psicofármacos, indica uma experiência referida ao que já foi ou é vivido por cada pessoa participante previamente ao estar no grupo, ao passado. Trata-se, portanto, de uma experiência mais privativa e individualizada, à medida que está localizada em cada sujeito, sendo nada ou pouco compartilhada. O segundo contexto, o dos Grupos de Intervenção com o Guia GAM, remete à experiência presente no aqui e agora dos grupos de intervenção, tecida grupalmente a partir dos relatos da experiência passada; e, finalmente, o terceiro contexto, o da participação na pesquisa, aponta para a experiência futura localizada no vir-a-ser de cada um e de todos, produzido a partir e para além dos grupos GAM, por todos os efeitos posteriores à experiência presente que, mesmo singular, seria agora coletivizada.

Santo Agostinho, já citado em um dos artigos de nosso estudo (ONOCKO-CAMPOS et 
alli., 2013), aponta para algo paradoxal acerca do tempo que pode interessar a esta ideia que sugerimos: o tempo, no mesmo instante em que é, já foi e não é ainda, uma vez que o presente nos escapa e o passado e o futuro não existiriam senão na continuidade daquele que observa o tempo passar. Nesta perspectiva, é o presente que se afirma como potência, é ele o senhor do tempo. Tanto passado quanto futuro se dão em referência a ele, a tudo aquilo que é. A memória, a intuição direta e a esperança citadas por Santo Agostinho poderiam também ser aproximadas dos três contextos da experiência GAM. No primeiro, a memória seria o vivido que os usuários trazem de sua relação com o uso de medicamentos; no segundo, a intuição direta estaria ligada àquilo que se passa durante os grupos GAM, na improvisação do encontro grupal; e, no terceiro, a esperança estaria relacionada a tudo aquilo que usuários, trabalhadores e pesquisadores depositam na intervenção, numa projeção em relação ao futuro - a esperança de transformar o presente e a relação com seus tratamentos, que aparece a partir do encontro com a estratégia GAM e seus dispositivos.

\section{O Comitê Cidadão e a experiência do sujeito de direitos}

Um segundo achado, quando de nossa busca, implica principalmente dois de nossos planos da experiência e o último dos três contextos mencionados, quais sejam: os planos da experiência dos usuários e da experiência da pesquisa e o contexto de participação na pesquisa. Em relação a esta última e aos processos decisórios que lhe são concernentes, criou-se um dispositivo por meio do qual se agenciou formalmente a participação dos usuários e familiares, chamado Comitê Cidadão.

O Comitê Cidadão era composto por nove membros com direito a voto: oito usuários de serviços de Saúde Mental e um familiar. Junto a este Comitê, existiam também o Comitê Científico, composto por experts do campo da saúde mental, com função consultiva, convocado a participar de atividades específicas e pontuais, como avaliação de projetos de pesquisa; e o Comitê Gestor, composto por representantes dos diferentes segmentos (pesquisadores, usuários, familiares e profissionais), com função de orientação, planejamento e avaliação. Os membros do Comitê Gestor e do Comitê Cidadão participavam de forma ativa das Reuniões Multicêntricas e Videoconferências. As primeiras constituíam um espaço de participação aberta a todos os integrantes da ARUCI-SMC no Brasil, acontecendo a cada dois meses, em média. As segundas, de frequência bianual, eram o espaço de encontro entre todos os membros da ARUCI-SMC, do Brasil e do Québec, Canadá, que encaravam o desafio de vencer a distância 
- não apenas geográfica, mas cultural e linguística - para instituir o diálogo entre os grupos dos dois países. As duas outras instâncias ainda envolvidas na gestão do trabalho eram a Direção ARUCI-SMC BR, composta por pesquisador-diretor e por usuário-diretor, e o Comitê Diretor Brasil-Canadá, reunindo a direção dos dois países. (PASSOS et alli, 2013: 2924)

$\mathrm{O}$ artigo do qual se recolhem as informações que constam acima discute o Comitê Cidadão (CC) como uma estratégia cogestiva de participação na pesquisa. Nele, encontramos a ideia de "produção da experiência do sujeito de direitos". Aqui defende-se o potencial da estratégia e se utiliza o termo experiência para designar algo com o caráter de transformação, de produção de outros possíveis com os sujeitos em questão. Contudo, há condições para que isso se efetive: não basta simplesmente uma aproximação com a GAM, mas a realização dos grupos e as demais interações sustentadas pelo princípio de cogestão. Somente desta forma a GAM pode atuar como um catalisador da produção de autonomia nos serviços de saúde mental. Ainda que não resolva a questão de forma permanente, ela é um dispositivo de mediação para a emergência da experiência como produção individual que se coletiviza no processo. Cabe dizer que a experiência só é possível de acontecer se isso envolver mais de um sujeito. Importa coletivizar vividos, partilhar vida para que se constitua experiência.

Ainda nesse artigo, é possível olhar para as dimensões temporais de passado e presente anteriormente referidas, quando, ao falar da experiência, os autores situam também o insight dos usuários como aquilo que vem junto da primeira, ou seja, passado e presente fazem aí uma composição. O insight aparece como fundamental para a construção do trabalho e do conhecimento em saúde mental. Para além daquilo que o usuário carrega consigo de sua experiência prévia, passada, têm grande valor as suas produções no aqui e agora de uma relação lateralizada com o coletivo envolvido. Nesta referência ao insight, o destaque está no presente do presente, do que se dá como efeito do encontro, o não-controlado que irrompe no sujeito e lhe permite ressignificar marcas anteriores.

\section{A experiência de escrita e autoria}

Ainda sobre o plano da experiência da pesquisa, localizamos no artigo citado mais acima o emprego da palavra experiência referindo-se à experiência de lateralização cogestiva, bem como a derivação para as três experiências de pesquisador: o pesquisador-universitário, o pesquisador-usuário/familiar e o pesquisador-trabalhador.

[...] A experiência de lateralização cogestiva na pesquisa permitiu aparecer diferentes experiências de pesquisador: pesquisador universitário ao lado de pesquisadores usuários e 
pesquisadores familiares. (PASSOS et alli, 2013: 2925)

Aqui, falar em experiência de lateralização cogestiva tem o mesmo sentido que já foi afirmado sobre a importância de utilizar a cogestão como princípio e estratégia de trabalho. E é a partir dela também que vão se tornar possíveis o desdobrar-se da experiência de pesquisador, não mais apenas restrita ao universitário, mas permitindo aos usuários, familiares e trabalhadores ocuparem também esta posição, mesmo que de forma particular. Isso vai produzir transformações no próprio saber/fazer do pesquisador acadêmico, que agora não mais realiza sua atividade principal da mesma forma que antes, pois precisa se reinventar ao partilhar algumas tarefas e atividades com os demais pesquisadores.

Destas três experiências de pesquisador, uma quarta vai emergir, à qual um artigo será especialmente dedicado: “A Experiência de produção de saber no encontro entre pesquisadores e usuários de serviços públicos de saúde mental: a construção do Guia GAM brasileiro" (FLORES et alli, 2015). Nesta escrita, os pesquisadores-universitários vão se colocar ao lado dos pesquisadores-usuários e dos pesquisadores-familiares para, juntos, realizar e discorrer sobre a experiência compartilhada da pesquisa e sobre o processo mesmo de elaboração de uma escrita coletiva, da qual participaram vinte e sete pessoas. Ela se constitui como uma experiência de escrita e autoria, travessia inédita para seus participantes:"Este artigo narra uma experiência inédita de pesquisa no Brasil: a escrita de um artigo que reuniu como autores pesquisadores acadêmicos, usuários e trabalhadores de saúde mental participantes de uma pesquisa multicêntrica desenvolvida com financiamento internacional.” (SILVEIRA et alli, 2014, resumo, grifo nosso).

A experiência de escrita conjunta aparece aqui como algo inédito e, mais adiante, como uma forma de territorializar a experiência da pesquisa, dar-lhe uma sustentação, um lugar, um sentido. Ao narrar o processo de escrita, que teve como mote inicial a experiência dos usuários de pesquisar, as autoras nos colocam a par da "virada" aí produzida quando um usuário inverte o questionamento, interrogando os pesquisadores: "e pra vocês, como é pesquisar desse jeito com a gente?". Essa escrita é organizadora, faz função para o grupo, ela é dispositivo. Encontramos ainda que é no escrever que registramos a experiência, a forma de se produzir seu território visível.

\section{Um quarto plano colhido a partir do fora-eixo}

Encontramos ainda outras referências ao termo experiência que não entendemos 
possível relacionar diretamente aos três planos já indicados. Quatro delas encontram-se em um mesmo artigo, de 2017, intitulado “A linguagem do fora: a interface entre drogas lícitas e ilícitas na saúde mental" (RODRIGUES \& PASSOS, 2017). São elas as seguintes: a experiência psicodélica, a experiência sensível/estética, a experiência do tempo subjetivo e a experiência beat.

Nesse artigo, os autores situam a dimensão da pesquisa denominada "fora-eixo", a qual diz respeito aos temas surgidos com base nas Memórias dos GIs, ainda na primeira etapa do projeto multicêntrico. Estes materiais eram analisados por meio de planilhas que continham os cinco eixos-estruturantes da pesquisa: formação, trabalhadores e gestão, direitos humanos, pesquisa/metodologia e fora-eixo, ficando reservado a este último aquilo que não se encaixasse nos eixos anteriores, bem como as construções de análise que se deram num plano sensível, um plano pré-reflexivo da experiência (RODRIGUES \& PASSOS, 2017). Neste último, percebeuse a importância da discussão de temas como o das drogas proscritas, que não estava de antemão previsto no projeto.

Também podem ser tomadas neste quarto-plano a experiência infantil, juntamente com a experiência escolar, que aparecem brevemente em um único artigo publicado sobre a GAM relacionada ao campo da infância, em 2017, de autoria de Chaves e Caliman. Nesse artigo, a ideia de experiência remete ao vivido e experimentado, que já tratamos acima, mas também a uma ideia de período, de algo com uma duração na vida, seja a infância, seja a escolarização. O estudo em questão aborda o uso do guia GAM em um grupo com familiares de crianças e adolescentes que frequentam um CAPSi e fazem uso de psicotrópicos.

Finalizamos assim a apresentação dos diferentes empregos da palavra experiência nos artigos GAM. Queremos ainda propor uma discussão de encerramento, partindo dos dois principais sentidos que encontramos para a palavra experiência na literatura, sendo um deles aquele que nos interessa desenvolver e colocar em ato nas práticas e na pesquisa em saúde mental.

\section{Considerações Finais}

Experiência: aquilo que o sujeito vive/sente/experimenta versus aquilo que resta da travessia de um perigo

Nossa pesquisa, na companhia de autores que já situamos anteriormente, sinaliza a possibilidade de propor dois campos semânticos no que diz respeito à experiência. Ainda que 
diferentes, eles não se contradizem e podem até ser complementares. Um deles acaba por designar algo mais corriqueiro e simples. É onde temos uma grande parte das referências ao termo experiência nos artigos publicados sobre a GAM, quando a palavra surge para enunciar algo da ordem do que o sujeito vive, sente ou experimenta. É quando seu significado está mais próximo àquele do léxico comum, que aparece não só na definição do dicionário, mas também nas falas cotidianas.

O segundo campo semântico localizado nestas produções está mais próximo da noção que construímos no início de nosso texto a partir das ideias de Benjamin, Agamben e Larrosa, quando o emprego da palavra experiência se refere àquilo que resta da travessia de um perigo, algo que transforma o sujeito e que é passível de ser compartilhado. As duas formas de utilizar o termo por vezes se intercalam, mas também aparecem juntas, interpostas, até confundidas. Isso nos permite dizer que a noção de experiência, também para os autores da GAM - na sua maioria pesquisadores universitários, pois são os que mais comumente escrevem e publicam pode ser nebulosa, pouco objetiva e carregada de ambiguidade. Ainda que não queiramos afirmar a obrigatoriedade de um único uso ou do emprego correto desta noção, entendemos que precisá-la é uma ação potente para o campo da saúde mental, podendo facilitar a comunicação entre os diferentes atores aí envolvidos, entre usuários, trabalhadores, familiares, gestores e pesquisadores.

Este artigo se ocupou de analisar os artigos publicados até o final do ano de 2018. Curiosamente, a última publicação analisada traz a palavra experiência já no título: "Gestão Autônoma da Medicação (GAM): uma experiência em saúde mental" (SILVEIRA \& MORAES, 2018). Nele, são inúmeros os empregos da palavra, com sentidos que passam de um campo semântico a outro, permanentemente. O que nos interessa nessa produção é exatamente o que afirma seu título: a GAM vem sendo uma experiência em saúde mental no Brasil. Nosso mergulho nessas publicações nos permite afirmar que a GAM tem se constituído como uma experiência para seus participantes, sejam eles usuários, trabalhadores, pesquisadores, familiares e mesmo gestores. A intensidade desta experiência pode variar, mas, de maneira geral, a GAM permite aos seus participantes realizar uma travessia da qual saem transformados. E aquilo que resta desta travessia são sujeitos engajados na direção co-gestiva das práticas em saúde mental. 


\section{Referências}

AGAMBEN, Giorgio. Infância e História: ensaio sobre a destruição da experiência. In: AGAMBEN, Giorgio. Infância e História: destruição da experiência e origem da história. Belo Horizonte: Editora UFMG, 2008

AGOSTINHO, Santo. As confissões. Edição eletrônica: Le livros. Disponível em: https://asdfiles.com/26gx9. Acesso em 21 de agosto de 2019

BENJAMIN, W. Experiência e Pobreza. In: BENJAMIN, W. Magia e técnica, arte e política: ensaios sobre literatura e história da cultura. São Paulo: Editora Brasiliense, 2011

BENJAMIN, Walter. O Narrador: considerações sobre a obra de Nikolai Leskov. In: BENJAMIN, Walter. Magia e técnica, arte e política: ensaios sobre literatura e história da cultura. São Paulo: Editora Brasiliense, 1994

CANADA. Regroupement des Ressources Alternatives en Sante Mentale du Québec. Gestion autonome de la médication de l'âme: mon guide personnel. Québec: RRASMQ, 2002

CHAVES, F. A. M.; CALIMAN, L. Entre Saúde Mental e a Escola: a Gestão Autônoma da Medicação. Rev. Polis e Psique, 7(3):136-160, 2017

FERRER, A.L., PALOMBINI, A.L., AZAMBUJA, M. Gestão Autônoma da Medicação: um olhar sobre dez anos de produção participativa em saúde mental a partir do Brasil. Rev. Polis e Psique. v.10, n. 2, p. 1-8, 2020

FLORES, A. et alli. ; A experiência da produção de saber no encontro entre pesquisadores e usuários de serviços públicos de saúde mental: a construção do Guia Gam brasileiro. Cadernos HumanizaSUS do Ministério da Saúde, v. 5, p. 257-275, 2015

GAGNEBIN, Jeanne-Marie História e Narração em Walter Benjamin. São Paulo: Perspectiva, 2011

GOMES, Luciana Ogg. A infância do homem. Pro-Posições, v. 18, n. 3 (54) - set./dez. 2007

HEIDEGGER, Martin. A essência da linguagem. In: HEIDEGGER, Martin. A caminho da linguagem. Petrópolis: Vozes; Bragança Paulista: Editora Universitária São Francisco, 2003

HOUAISS, Antonio \& VILLAR, Mauro de Sales. Dicionário Houaiss da Língua Portuguesa. Rio de Janeiro: Objetiva, 2001

KINOSHITA, Roberto Tykanori. Contratualidade e reabilitação psicossocial. Em Pitta A (Ed.), Reabilitação psicossocial no Brasil. São Paulo: Hucitec, 1996

LARROSA, Jorge. Tremores: escritos sobre experiência. Belo Horizonte: Autentica Editora, 2014

ONOCKO-CAMPOS, Rosana Teresa.; FURTADO, Juarez Pereira. Narrativas: apontando alguns caminhos para sua utilização na pesquisa qualitativa em Saúde. In:ONOCKO CAMPOS, R. T. ; FURTADO, J. P. ; PASSOS, E. ; BENEVIDES, R.. (Org.). Pesquisa Avaliativa em Saúde Mental: desenho participativo e efeitos da narratividade. 1 ed. São Paulo: Aderaldo \& Rothschild Editores, 2008, v. 1, p. 321-334

ONOCKO CAMPOS, Rosana Teresa et alli. Adaptação multicêntrica do Guia para a Gestão Autônoma da Medicação. Interface. Comunicão Saúde e Educação, v. 17, n’43, p. 96780, out/dez 2012 
ONOCKO-CAMPOS, Rosana Teresa et alli. Narrativas no estudo das práticas em saúde mental: contribuições das perspectivas de Paul Ricoeur, Walter Benjamim e da antropologia médica. Ciênc. saúde coletiva, Rio de Janeiro , v. 18, n. 10, p. 28472857, Oct. 2013

ONOCKO-CAMPOS, Rosana Teresa et alli. A Gestão Autônoma da Medicação: uma intervenção analisadora de serviços em saúde mental. Ciência \& saúde coletiva, Rio de Janeiro , v. 18, n. 10, p. 2889-2898, Oct. 2013

ONOCKO-CAMPOS, Rosana Teresa et alli. Guia Brasileiro da Gestão Autônoma da Medicação. DSC/FCM/UNICAMP; AFLORE; DP/UFF; DPP/UFRGS, 2014. Disponível em: http://www.fcm.unicamp.br/fcm/laboratorio-saude-coletiva-esaudemental-interfaces

PALOMBINI, Analice et alli. Relações entre pesquisa e clínica em estudos em cogestão com usuários de saúde mental. Ciênc. Saúde coletiva_(18) 10, pp. 2899-2908, 2013

PALOMBINI, Analice et alli. Relatório final da pesquisa "Implementação e descentralização da estratégia da gestão autônoma da medicação (GAM) no estado do RS: efeitos de disseminação”. CNPq, 2019

PALOMBINI, A.L; RODRIGUEZ DE BARRIO, L. Gestão Autônoma da Medicação, do Quebec ao Brasil. Saúde em Debate. (no prelo)

PASSOS, Eduardo et ali. Autonomia e cogestão na prática em saúde mental: o dispositivo da gestão autônoma da medicação. Aletheia (ULBRA), v. 41, p. 24-38, 2013

RODRIGUES, Sandro; PASSOS, Eduardo. A linguagem do fora: a interface entre drogas lícitas e ilícitas em saúde mental. Estudos da Língua(gem), [S.1.], v. 15, n. 1, dez. 2016. ISSN 1982-0534

SERRANO-MIGUEL, M., PIÉ-BALAGUER, A., e MARTÍNEZ-HERNAEZ, A., (Org.) Guía para la gestión colaborativa de la medicación en salud mental. Tarragona: Publicacions URV; Barcelona: Universitat Oberta de Catalunya, 2020

SILVEIRA, Marilia et alli. EscreverCOM: uma experiência ético-política de pesquisa. Revista Mnemonise (UERJ). v. 10, n. 1, 2014

SILVEIRA, Marilia; MORAES, Marcia. Gestão Autônoma da Medicação (GAM): uma experiência em saúde mental. Estudos Contemporâneos da Subjetividade. v. 8, n.1; 138152,2018

Lívia Zanchet Doutora em Psicologia Social e Institucional (UFRGS) em cotutela com a Université Côte d'Azur/França Psicóloga Clínica nos Foyers Les Baous em Vence/França E-mail: liviazanchet@gmail.com

Analice de Lima Palombini Doutora em Saúde Coletiva (UERJ) Professora do Instituto de Psicologia (UFRGS)

E-mail: analice.palombini@gmail.com 
${ }^{1}$ No contexto da Reforma Psiquiátrica Brasileira, o conceito de autonomia define-se na referência à pluralidade de vínculos que se é capaz de estabelecer: quanto mais vínculos e redes de relações uma pessoa constrói, mais autônoma ela se torna (KINOSHITA, 1996).

${ }^{2}$ CANADA. Regroupement des Ressources Alternatives en Santé Mentale du Québec. Gestion autonome de la médication de l'âme: mon guide personnel. Québec: RRASMQ, 2002.

${ }^{3}$ Conforme Palombini e Del Barrio, no prelo.

${ }^{4}$ https://observatoriogam.unifesp.br/ 